\title{
Cajaninstilbene Acid Prevents Corticosterone-Induced Apoptosis in PC12 Cells by Inhibiting the Mitochondrial Apoptotic Pathway
}

\author{
Bao-Ping Jiang Ya-Min Liu Liang Le Zong-Yang Li Jian-Yong Si Xin-Min Liu \\ Qi Chang Rui-Le Pan
}

Institute of Medicinal Plant Development, Chinese Academy of Medical Science, Peking Union Medical College, Beijing, China

\section{Key Words}

Cajaninstilbene acid $\bullet$ Corticosterone $\bullet$ Mitochondrial apoptotic pathway $\bullet$ PC12 cells

\begin{abstract}
Background/Aims: Cajaninstilbene acid (3-hydroxy-4-prenyl-5-methoxystilben-2 -carboxylic acid, CSA), a natural stilbene isolated from the leaves of Cajanus cajan, has attracted considerable attention for its wide range of pharmacological activities. This study investigated whether CSA protects against corticosterone (CORT)-induced injury in PC12 cells and examined the potential mechanisms underlying this protective effect. Methods: Cell viability and cytotoxicity were detected using a 3-(4,5-desethyithiazol-2-yl)-2,5-diphenyltetrazolium bromide (MTT) assay and a lactate dehydrogenase (LDH) assay kit, respectively. PC12 cell apoptosis was measured using Hoechst 33342 staining and a DNA fragmentation assay kit, and intracellular $\mathrm{Ca}^{2+}$ concentrations were assessed by fluorescent labelling. Next, the mitochondrial permeability transition pores (mPTPs) and mitochondrial membrane potentials $\left(\Delta \Psi_{\mathrm{m}}\right)$ were detected using a colorimetric mPTP detection kit and a 5, 5',6,6'-tetrachloro-1,1',3,3'- tetraethylbenzimidazolylcarbocyanine iodide (JC-1) kit, respectively. Finally, cytochrome c, caspase-3 and inhibitor of caspase-activated deoxyribonuclease (ICAD) expression levels were monitored by western blot analysis. Results: Treatment with $100 \mu \mathrm{mol} / \mathrm{I}$ CORT induced cytotoxicity in PC12 cells. However, CSA dose-dependently increased cell viability and decreased LDH release as well as CORTinduced apoptosis. Mechanistically, compared with the CORT-treated group, CSA strongly attenuated intracellular $\mathrm{Ca}^{2+}$ overload and restored mitochondrial functions, including mPTPs and $\Delta \Psi \mathrm{m}$. Furthermore, the down-regulation of cytochrome $\mathrm{c}$ and ICAD protein expression and the blockage of caspase-3 activity were observed upon CSA treatment. Conclusions: In summary, our data are the first to show that the in vitro antidepressant-like effect of CSA may be attributed to the cytoprotection of neurons and that such neuroprotective mechanisms are correlated with intracellular $\mathrm{Ca}^{2+}$ homeostasis and mitochondrial apoptotic pathways.
\end{abstract}

Copyright (C) 2014 S. Karger AG, Basel

Rui-Le Pan

Institute of Medicinal Plant Development, Peking Union Medical College

Chinese Academy of Medical Sciences. No 151, North Road Malianwa,

Haidian District, Beijing 100193 (China)

Tel. +86-10-57833275, Fax +86-10-57833299, E-Mail rlpan@implad.ac.cn 


\section{Cellular Physiology and Biochemistry}

Cell Physiol Biochem 2014;34:1015-1026

\begin{tabular}{l|l}
\hline DOI: $10.1159 / 000366317$ & (C) 2014 S. Karger AG, Basel
\end{tabular}

www.karger.com/cpb

Jiang et al.: CSA Prevents Apoptosis by Inhibiting the Mitochondrial Apoptotic Pathway

\section{Introduction}

Glucocorticoids are steroid hormones produced by the adrenal cortex and are critical for the regulation of development, metabolism and immune function [1]. However, high levels of corticosterone (CORT), a principal glucocorticoid, can cause pathological damage to hippocampal neurons both in vitro and in vivo $[2,3]$ and can induce depression-like behaviour in animals, which can be reversed by treatment with antidepressants $[4,5]$. Thus, drugs that can inhibit CORT-induced neuronal damage may provide protection against depression.

Pigeon pea [Cajanus cajan (L.) Millsp.] is an important grain legume crop in semitropical and tropical areas of the world. Extracts of pigeon pea are commonly used to treat diabetes, febrifuge, dysentery, hepatitis and measles worldwide [6-8]. The active constituents of pigeon pea include certain types of flavonoids and stilbenes $[9,10]$. Some pharmacological studies have revealed that 3-hydroxy-4-prenyl-5-methoxystilben-2-carboxylic acid (CSA) (Fig. 1), one of the major stilbenes found in pigeon pea, has hypoglycaemic activities [11] as well as anti-inflammatory and analgesic effects [12]. Furthermore, a recent study by our research group demonstrated that the CSA-containing fraction of Cajanus cajan can significantly ameliorate the cognitive deficits and prevent the neuronal apoptosis caused by $A \beta 25-35$ injection in mice [13]. Accordingly, we suggest that CSA may be a potential cytoprotective agent for neurological diseases that are associated with CORT-induced neurotoxicity.

The differentiated rat pheochromocytoma (PC12) cell line possesses typical neuronal features and expresses high levels of glucocorticoid receptors. Treatment of PC12 cells with high concentrations of glucocorticoid induces neuronal damage that mimics that observed in depressive disorders. Indeed, this treatment has been used to generate an in vitro experimental model of depression [14-17], and this neuronal cell line has been used in a variety of studies [18-20].

The present study aimed to examine the protective effects of CSA and further investigate its underlying mechanisms in CORT-damaged PC12 cells. The results revealed that CSA partially inhibited apoptosis in CORT-induced PC12 cells. Importantly, intracellular $\mathrm{Ca}^{2+}$ homeostasis and inhibition of the mitochondrial apoptotic pathway play major roles in this process.

\section{Materials and Methods}

\section{Materials}

The PC12 cell line was purchased from the Cell Bank of the Chinese Academy of Sciences (Shanghai), and 3-(4,5-desethyithiazol-2-yl)-2,5-diphenyltetrazolium bromide (MTT), dimethyl sulphoxide (DMSO), desipramine (DIM) and CORT were obtained from Sigma-Aldrich Inc. (St. Louis, MO, USA). Fura-2/AM was purchased from the Beyotime Institute of Biotechnology (Jiangsu, China). Dulbecco's modified Eagle's medium (DMEM), fetal bovine serum, heat-inactivated horse serum, penicillin and streptomycin were purchased from Gibco (Grand Island, NY, USA). CSA was extracted from the leaves of Cajanus cajan in our laboratory, and the resulting purity exceeded $98 \%$. Deionised water was used in all experiments. All other chemicals and reagents were of analytical grade.

\section{Cell culture and treatment}

PC12 cells were maintained in DMEM that was supplemented with penicillin $(100 \mathrm{U} / \mathrm{ml})$, streptomycin $(100 \mu \mathrm{g} / \mathrm{ml}), 5 \%$ fetal bovine serum and $5 \%$ horse serum at $37^{\circ} \mathrm{C}$ in a humidified atmosphere of $95 \%$ air and $5 \% \mathrm{CO}_{2}$. Cells in the exponential phase of growth were used in all experiments. To study the neuroprotective effect of CSA, PC12 cells were divided into the following groups, as previously described [21]: untreated; CORT $(100 \mu \mathrm{mol} / \mathrm{l})$ plus DIM (1.0, 2.0, 4.0, 8.0 and $16.0 \mu \mathrm{mol} / \mathrm{l})$; and CORT (100 $\mu \mathrm{mol} / \mathrm{l})$ plus CSA (1.0, 2.0, 4.0, 8.0 and $16.0 \mu \mathrm{mol} / \mathrm{l})$. In all experiments, CORT was added $48 \mathrm{~h}$ prior to treatment with CSA or DIM.

Determination of cell viability via MTT assay

Briefly, PC12 cells were seeded into 96-well culture plates at a density of $1 \times 10^{4}$ cells/well. At the end of the treatment, the cells were gently washed with phosphate-buffered saline (PBS). After washing, 


\section{Cellular Physiology and Biochemistry}

Cell Physiol Biochem 2014;34:1015-1026

\begin{tabular}{l|l}
\hline DOI: $10.1159 / 000366317$ & (c) 2014 S. Karger AG, Basel
\end{tabular}

www.karger.com/cpb

Jiang et al.: CSA Prevents Apoptosis by Inhibiting the Mitochondrial Apoptotic Pathway
MTT (final concentration of $0.5 \mathrm{mg} / \mathrm{ml}$ ) solution was added to each well. The plate was maintained at $37^{\circ} \mathrm{C}$ for $4 \mathrm{~h}$. The dark blue formazan crystals formed within intact cells were solubilised with DMSO. The absorbance was measured at $570 \mathrm{~nm}$ using a microplate reader (BIO-TEK USA). Cell viability is expressed as a percentage of the nontreated control.

Assessment with Hoechst 33342

Fig. 1. Chemical structure of cajaninstilbene acid.

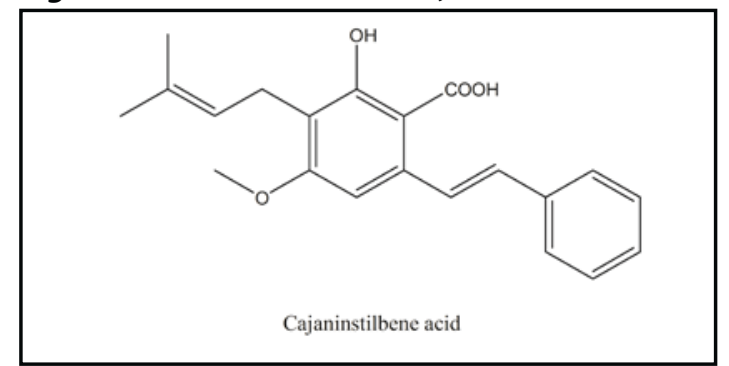

To further investigate the protective effect of CSA, Hoechst 33342, which can be used to distinguish between apoptotic and normal cells based on nuclear chromatin condensation and fragmentation, was used for qualitative and quantitative analyses of apoptotic cells. Briefly, PC12 cells were cultured in 6-well plates for $36 \mathrm{~h}$. At the end of the treatment, the cells were incubated with $10 \mathrm{ug} / \mathrm{mL}$ Hoechst 33342 for 15 min, washed twice with PBS and then visualised with fluorescence microscopy (Leica, Heidelberg, Germany). At least 200 cells were examined to identify apoptotic nuclei in five randomly selected fields in each treatment. The numbers of apoptotic nuclei are expressed as percentages of the total number of counted nuclei.

Lactate dehydrogenase (LDH) activity assay

LDH activity was measured using an LDH diagnostic kit (A020, Nanjing Jiancheng Bioengineering Institute, China) according to the manufacturer's protocol. Briefly, PC12 cells were seeded into 24-well culture plates at a density of $1 \times 10^{5}$ cells/well. At the end of the treatment, the supernatants were collected for LDH measurement at $340 \mathrm{~nm}$ in cell-free media. The cell pellet and cells remaining in the multiwell plate were lysed in $0.5 \mathrm{ml}$ of lysis buffer ( $0.5 \%$ Triton X-100 in $0.1 \mathrm{M}$ potassium phosphate buffer, pH 7.0). The amount of intracellular LDH released into the extracellular medium is expressed as a percentage (\%) of total LDH activity (LDH in the medium + LDH in the cell) according to the following equation: \% LDH released $=($ LDH activity in the medium/total LDH activity $) \times 100$.

\section{Quantification of DNA fragmentation}

DNA fragmentation was quantified using the Cell Death Detection ELISA ${ }^{\text {Plus }}$ kit (Roche Applied Sciences, Basel, Switzerland) according to the manufacturer's protocol. At the end of treatment, the cells were washed with D-Hanks solution and incubated with $200 \mu \mathrm{l}$ of lysis buffer for $30 \mathrm{~min}$ at room temperature. The plates were centrifuged at $200 \mathrm{~g}$ for $10 \mathrm{~min}$ at $4^{\circ} \mathrm{C}$. An aliquot $(20 \mu \mathrm{l})$ of the supernatant from each well was transferred to a streptavidin-coated microplate and incubated with a mixture of anti-histone-biotin and anti-DNA-peroxidase. The apoptotic nucleosomes were captured via their histone components using the anti-histone-biotin antibody embedded in the streptavidin-coated microplates. Simultaneously, antiDNA-peroxidase was bound to the DNA part of the nucleosomes. After removing the unbound antibodies, the amount of peroxidase retained in the immunocomplexes was quantitated by adding 2, 2'-azinobis (3-ethylbenzthiazoline-6-sulphonic acid) (ABTS) as the substrate, and the absorbance of the reaction mixtures was measured at $405 \mathrm{~nm}$ using a microplate reader. The absorbance is directly proportional to the number of apoptotic nucleosomes. The degree of DNA fragmentation is expressed as a percentage of the non-treated control.

\section{Measurement of intracellular calcium levels}

The concentration of intracellular calcium $\left(\left[\mathrm{Ca}^{2+}\right]_{\mathrm{i}}\right)$ was determined using the fluorescent $\mathrm{Ca}^{2+}$ chelator Fura-2/AM. Fura-2 binds to intracellular $\mathrm{Ca}^{2+}$ to form a fluorescent compound, and the fluorescence intensity of this compound was determined at an excitation wavelength of $340 \mathrm{~nm}$ and an emission wavelength of 510 $\mathrm{nm}$ using a microplate reader (Infinite $1000 \mathrm{M}$, Tecan, AUSTRIA). The cells were rinsed with Krebs-Ringer buffer (137 M NaCl, $5 \mathrm{mM} \mathrm{KCl}, 1 \mathrm{mM} \mathrm{MgCl}, 1.5 \mathrm{mM} \mathrm{CaCl}_{2}, 10 \mathrm{mM}$ HEPES and $25 \mathrm{mM}$ D-glucose, pH adjusted to 7.4) and incubated with $5 \mu \mathrm{M}$ Fura- $2 / \mathrm{AM}$ at $37^{\circ} \mathrm{C}$ for $60 \mathrm{~min}$. Subsequently, the cells were washed twice with Krebs-Ringer buffer for fluorescence measurement. The results are expressed as percentages of the non-treated control. 


\section{Cellular Physiology and Biochemistry}

Cell Physiol Biochem 2014;34:1015-1026

\begin{tabular}{l|l}
\hline DOI: $10.1159 / 000366317$ & (c) 2014 S. Karger AG, Basel
\end{tabular}

www.karger.com/cpb

Jiang et al.: CSA Prevents Apoptosis by Inhibiting the Mitochondrial Apoptotic Pathway

Determination of mitochondrial membrane potential $(\Delta \Psi m)$

Changes in $\Delta \Psi \mathrm{m}$ in CORT-treated PC12 cells were determined using 5,5',6,6'-tetrachloro-1,1',3,3'tetraethylbenzimidazolyl-carbocyanine iodide (JC-1). After the indicated treatment, the cells were incubated at $37^{\circ} \mathrm{C}$ with a working solution of JC- 1 (Molecular Probes, Eugene, OR, USA) for $15 \mathrm{~min}$ and then washed twice with PBS. Subsequently, the cells were resuspended in PBS at a concentration of approximately $1 \times 10^{6}$ cells/ml, labelled with JC-1 and analysed by FACSCalibur flow cytometry (BD Biosciences).

Measurement of mitochondrial permeability transition pore (MPTP) opening

mPTP opening in CORT-treated PC12 cells was determined using the mPTP Colorimetric Detection Kit (Genmed Scientifics, Inc.), which is based on the quenching of calcein fluorescence by cobalt. All procedures completely complied with the manufacturer's instructions. The cells were washed twice with Reagent A, and Reagents $\mathrm{B}$ and $\mathrm{C}\left(1: 50 ; 500 \mu \mathrm{l}\right.$ per well) were added for $20 \mathrm{~min}$ at $37^{\circ} \mathrm{C}$ for staining. The cells were then washed twice with pre-warmed Reagent $\mathrm{A}$, and the fluorescence intensity was measured using a microplate reader with excitation and emission wavelengths of 488 and $505 \mathrm{~nm}$, respectively.

\section{Western blot analyses}

At the end of the treatment, the cells were harvested, washed once with PBS and subsequently lysed with cell lysis buffer containing $50 \mathrm{mM}$ Tris (pH 7.4), $150 \mathrm{mM} \mathrm{NaCl}, 0.1 \%$ SDS, 1 \% Triton X-100, $10 \mathrm{mM}$ EGTA and a protease inhibitor cocktail. The cytosolic fraction was isolated as previously described [22]. The total lysates and cytosolic fractions were collected for protein quantification via Bradford protein assays [23] and were boiled for $10 \mathrm{~min}$ after the addition of loading buffer. Solubilised proteins $(30 \mu \mathrm{g})$ were separated by 8 or $15 \%$ SDS-PAGE at $100 \mathrm{~V}$ for $1.5 \mathrm{~h}$ at $25^{\circ} \mathrm{C}$ and then electrophoretically transferred to nitrocellulose membranes for 60 or $90 \mathrm{~min}$ at $200 \mathrm{~mA}$ and $4^{\circ} \mathrm{C}$. The membranes were blocked with $5 \%(\mathrm{w} / \mathrm{v}) \mathrm{milk}$ in 138 $\mathrm{mM} \mathrm{NaCl}, 25 \mathrm{mM}$ Tris, $\mathrm{pH} 7.5$ and $0.1 \%(\mathrm{w} / \mathrm{v})$ Tween- 20 at $25^{\circ} \mathrm{C}$ for $1 \mathrm{~h}$ and then probed overnight at $4^{\circ} \mathrm{C}$ with anti-inhibitor of caspase-activated deoxyribonuclease (ICAD) (1:1000, GTX103668, GeneTex), anticytochrome c ( $2 \mu \mathrm{g} / \mathrm{ml}, 3025-100$, BioVision), anti-caspase-3 (1:500, 9662, Cell Signaling Technology) and anti- $\beta$-actin (1:1000, CW0096A, CWBio) antibodies to normalise the total lysate. The antibody reaction was visualised with ECL chemiluminescence (GE Healthcare, Little Chalfont, UK). Densitometric analyses were performed with ImageJ2 software for Windows.

\section{Cellular caspase-3 activity determination}

Caspase-3 activity was measured using an Apo-ONE® Homogeneous Caspase-3/7 Assay (Promega, Madison, USA) according to the manufacturer's protocol. Briefly, PC12 cells were seeded into 96-well black plates at a density of $1 \times 10^{4}$ cells/well. At the end of the treatment, $100 \mu$ l of Apo-ONE® Caspase-3/7 Reagent was added to each well of 96 -well black plates containing $100 \mu \mathrm{l}$ of cells in culture medium. The contents of the wells were gently mixed with a plate shaker at $300 \times \mathrm{g}$ for $5 \mathrm{~h}$ at room temperature. The fluorescence of each well was determined using a microplate reader at an excitation wavelength of $499 \mathrm{~nm}$ and an emission wavelength of $521 \mathrm{~nm}$. The results are expressed as percentages of the non-treated controls.

\section{Statistical analyses}

Data are expressed as the mean \pm the standard deviation (SD). One-way analyses of variance (ANOVAs) followed by Dunnett's test were used to test differences between the groups. Differences were considered to be statistically significant at $P<0.05$. All experiments were performed a minimum of three times.

\section{Results}

CSA ameliorated CORT-induced cytotoxicity in PC12 cells

The possible protective effect of CSA against CORT-induced cell death was assessed in PC12 cells. The cells were treated with increasing concentrations of CSA or DIM (0-16 $\mu \mathrm{mol} / \mathrm{l})$ after the addition of CORT $(100 \mu \mathrm{mol} / \mathrm{l})$ for $48 \mathrm{~h}$. DIM, a known antidepressant, was used as a positive control. CORT treatment caused significant cytotoxicity in PC12 cells (53.9 $\%$ of the control), as assessed by the MTT test, whereas treatment with DIM or CSA increased cell viability (Fig. 2A). The results revealed that CSA exhibited stronger cytoprotective effects 
Fig. 2. Neuroprotective effects of CSA against CORT-induced injury in PC12 cells. (A) Cell viabilities assayed via MTT. (B) Cell viabilities according to LDH leakage assays. The values given are the means \pm the SDs (n=6). ${ }^{\# \# \# ~} P<0.001$ compared to the control group; ${ }^{*} P<0.05$ and ${ }^{* *} P<0.01$ compared to the CORT group. CSA: cajaninstilbene acid, CORT: corticosterone. DIM: desipramine.

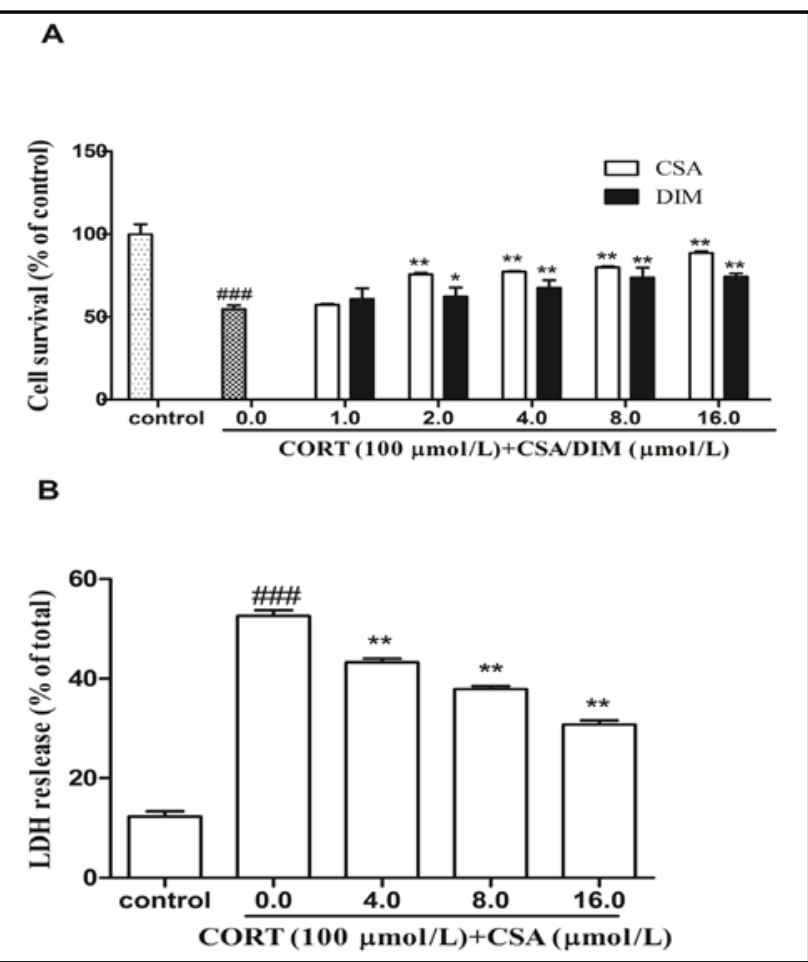

against CORT-induced apoptosis than DIM at the same concentrations and also indicated that CSA (2.0-16.0 $\mu \mathrm{mol} / \mathrm{l})$ possesses dose-dependent neuroprotective effects.

The protective effect of CSA was also demonstrated by detecting LDH leakage caused by CORT, which was significantly increased compared with that observed in the control group $(P<0.001)$. In contrast, when cells were treated with CSA $(4.0,8.0$ and $16.0 \mu \mathrm{mol} / \mathrm{l})$ in the presence of CORT, the percentages of LDH leakage dropped to $43.4 \%, 37.9 \%$ and $31.1 \%$, respectively (Fig. 2B). These results indicated that CSA has a protective effect against CORTinduced neurotoxicity in PC12 cells by reducing LDH release.

CSA inhibited the apoptosis and DNA fragmentation induced by CORT in PC12 cells

To further investigate the protective effects of CSA, Hoechst 33342 staining was performed to examine morphological changes in PC12 cells. The fluorescence images revealed oval-shaped nuclei with homogeneous fluorescence intensity in the normal cells, whereas heterogeneous intensities and chromatin condensation were observed in the nuclei of the CORT-injured PC12 cells (Fig. 3A). The nuclei of the apoptotic cells (i.e., the Hoechstpositive cells) are indicated by arrowheads in the images and were counted for statistical analyses. The results revealed that CSA alleviated the morphological changes induced by CORT in PC12 cells. Apoptotic cells accounted for $0.02 \%$ of the cells in the control group and $34.5 \%$ of the CORT-treated cells. The number of apoptotic cells significantly decreased after treatment with $2.0,4.0,8.0$ and $16.0 \mu \mathrm{mol} / \mathrm{L} \mathrm{CSA}$, and the percentages decreased to $17.0 \%$, $13.5 \%, 8.8 \%$ and $7.1 \%$, respectively (Fig. 3B).

Similarly, CORT elevated the level of DNA fragmentation $(272.1 \%)$ in PC12 cells considerably compared with the control group $(P<0.001)$ (Fig. 3C). In the cells treated with various concentrations of CSA $(4.0,8.0$ and $16.0 \mu \mathrm{mol} / \mathrm{l})$ in the presence of CORT, DNA fragmentation was significantly decreased $(P<0.01, P<0.01$ and $P<0.05$, respectively) compared with that observed in the CORT group, with $222.2 \%, 192.9 \%$ and $128.2 \%$ of the cells in the CORT+ CSA group showing fragmented DNA, respectively.

Effect of CSA on the intracellular $\mathrm{Ca}^{2+}$ concentration in CORT-damaged PC12 cells

Intracellular $\mathrm{Ca}^{2+}$ concentrations were measured using the Fura-2/AM fluorescence labelling assay. The ratio of fluorescence intensities related to intracellular $\mathrm{Ca}^{2+}$ was used 
Fig. 3. Effects of CSA on cell apoptosis and DNA fragmentation in corticosterone-treated PC12 cells. (A) Representative Hoechst 33342 staining images of cell apoptosis. (B) Quantification of Hoechst 33342 staining. The histogram shows the relative proportions of Hoechst 33342 stain-positive cells in the different treatment groups. Cell apoptosis (\%) detected by manually counting the relative proportions of Hoechst 33342 stain-positive cells in the different treatment groups. (C) Effects of CSA on DNA fragmentation. The results are expressed as the means \pm the SDs $(n=3)$. ${ }^{\# \# \#} P<0.001$ compared to the control group; ${ }^{* *} P<0.01$ compared to the CORT group. CSA: cajaninstilbene acid, CORT: corticosterone.

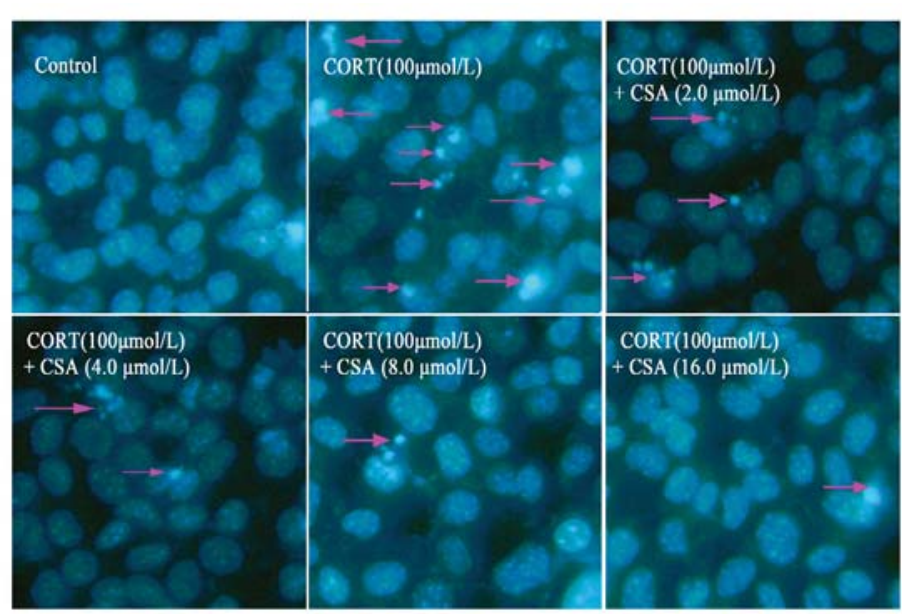

B
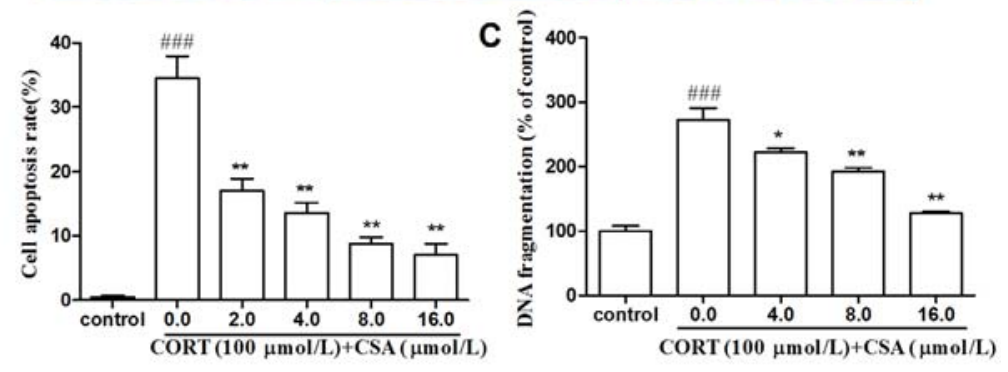

Fig. 4. Effect of CSA on $\left[\mathrm{Ca}^{2+}\right]_{\mathrm{i}}$ in CORT-treated PC12 cells. The values given are the means \pm the SDs ( $n=5) .{ }^{\# \#} P<0.01$ compared to the control group; ${ }^{*} P<0.05$ and ${ }^{* *} P<0.01$ compared to the CORT group. CSA: cajaninstilbene acid, CORT: corticosterone.

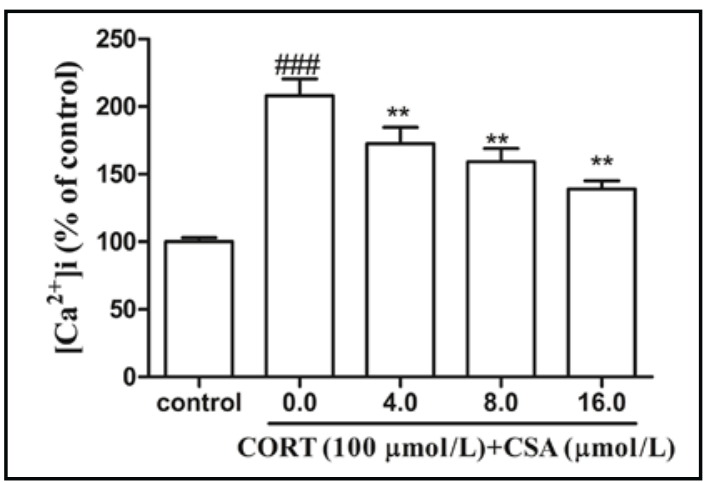

to represent the $\mathrm{Ca}^{2+}$ concentration in PC12 cells. As shown in Fig. 4, CORT significantly increased the concentration of intracellular $\mathrm{Ca}^{2+}(208.8 \%$ of the control), and various doses of $\operatorname{CSA}(4.0,8.0$ and $16.0 \mu \mathrm{mol} / \mathrm{l})$ decreased this concentration (to $172.7 \%, 159.3 \%$ and $139.0 \%$ of the control, respectively). The results indicated that CORT could increase the intracellular $\mathrm{Ca}^{2+}$ concentration, whereas CSA could significantly attenuate the intracellular $\mathrm{Ca}^{2+}$ overload induced by CORT in PC12 cells.

CSA inhibited the loss of $\triangle \Psi m$ and the opening of MPTPs in CORT-treated PC12 cells

The effect of CSA on $\triangle \Psi \mathrm{m}$ damaged by CORT was assayed by JC- 1 staining. The results showed that the exposure of PC12 cells to CORT caused a significant increase in the green/ red fluorescence ratio relative to that of the control group $(P<0.01)$, indicating that CORT induced the depolarisation of $\Delta \Psi \mathrm{m}$ (Fig. 5A). In contrast, the green/red fluorescence intensity ratios of cells cultured with $\operatorname{CSA}(4.0,8.0$ and $16.0 \mu \mathrm{mol} / \mathrm{l})$ were markedly attenuated 
A
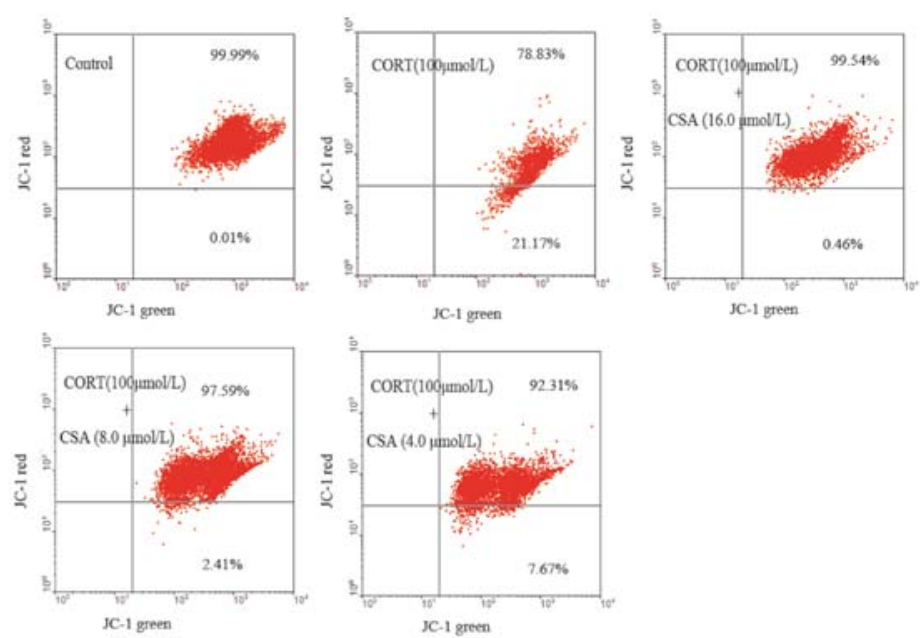

B

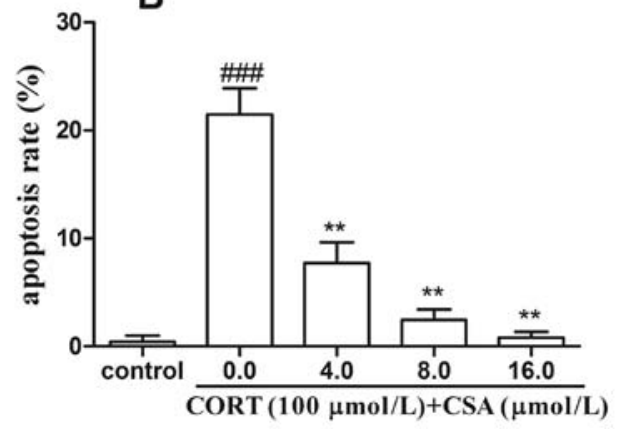

C

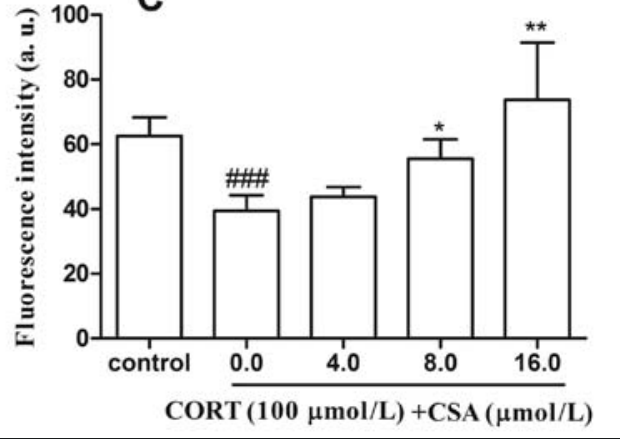

Fig. 5. Effects of CSA on mitochondrial membrane potentials in CORT-treated PC12 cells based on flow cytometry analyses. (A) The cells were pretreated with CSA; then, the cells were stained with 2 mmol/L JC- 1 for 30 min and analysed with flow cytometry. (B) JC-1 positive rate. The results are presented as fluorescence intensities (C). ${ }^{\# \# \# ~} P<0.01$ compared to the control group; ${ }^{*} P<0.05$ and ${ }^{* *} P<0.01$ compared to the CORT group. The values are the means \pm the SEMs, $n=5$. CSA: cajaninstilbene acid, CORT: corticosterone.

compared with the ratios of cells treated with the same CORT concentrations. Statistical analyses of fluorescence intensity revealed that the green/red fluorescence ratios of the CORT-treated group increased to $21.17 \%$, while they decreased to $7.67 \%, 2.41 \%$ and 0.46 $\%$ in the presence of different concentrations of CSA (4, 8 and $16 \mu \mathrm{mol} / \mathrm{l}$, respectively) (Fig. 5B). These results demonstrated that the anti-apoptotic effect of CSA was most likely due to the restoration of mitochondrial function. Therefore, we further explored mitochondrial mPTP opening using the calcein-cobalt quenching method and found that CORT decreased the mitochondrial fluorescence intensity compared to the controls $(P<0.001)$. In contrast, CSA significantly increased fluorescence intensity compared with the CORT group (Fig. 5C), suggesting that CSA markedly induced the closure of mPTPs.

CSA modulated apoptosis-related protein expression and caspase-3 activity in CORTtreated PC12 cells

As shown in Figs. 6A, 6B and 6C, cytosolic cytochrome c and cleaved ICAD expression levels were significantly increased in PC12 cells after treatment with $100 \mu \mathrm{mol} / \mathrm{l}$ CORT, and CSA reversed this effect. The release of cytochrome c can activate members of the caspase family that regulate many of the events that lead to the cellular and biochemical changes associated with apoptosis [24]. We examined caspase-3 activity and expression levels. Similar to cytochrome c, caspase- 3 activity was significantly increased when cells were treated with $100 \mu \mathrm{mol} / \mathrm{l}$ CORT, whereas CSA reversed these changes in caspase-3 activity (Fig. 6D). These 


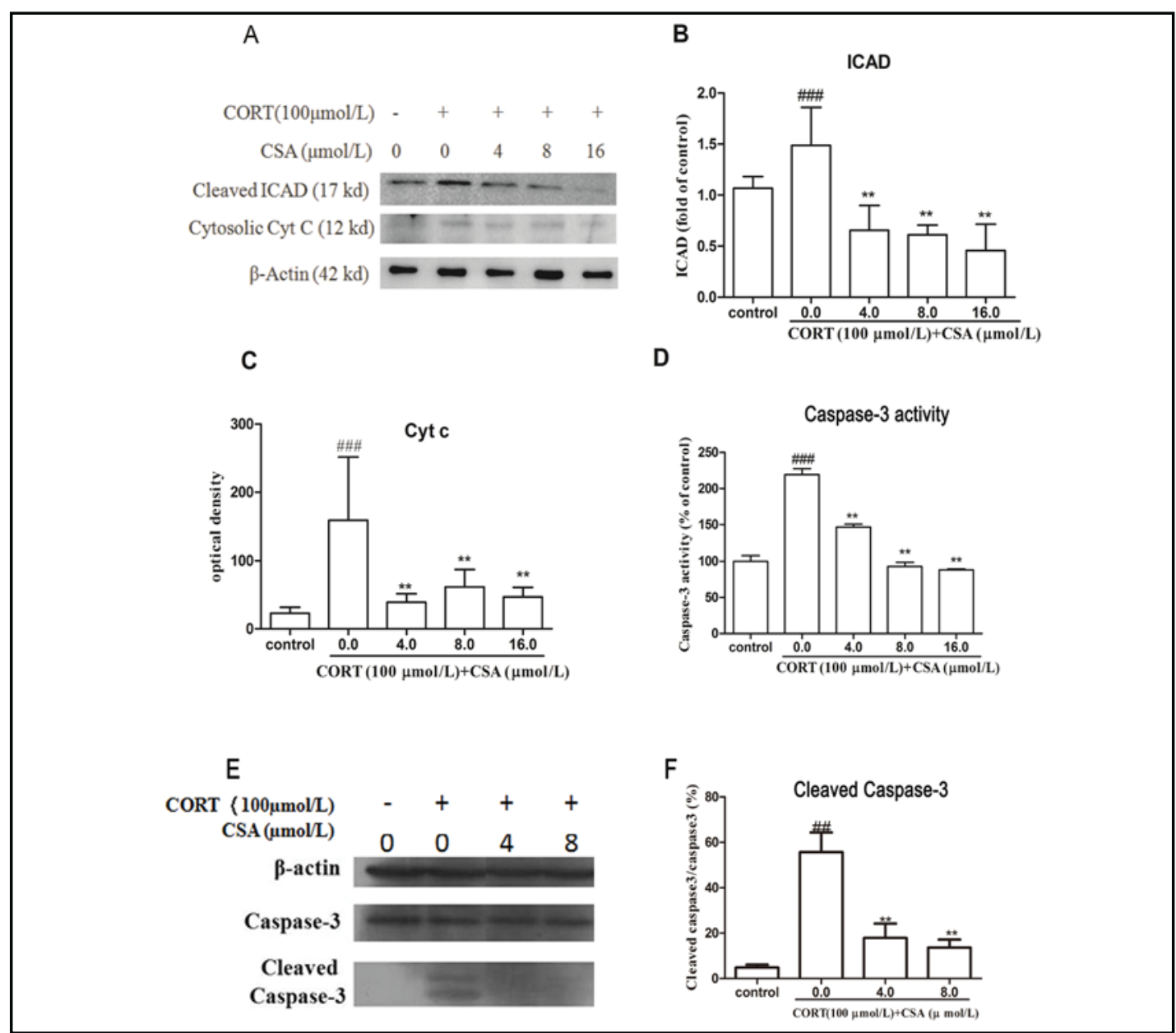

Fig. 6. Effect of CSA on the expressions of cytochrome $c$, caspase 3 and ICAD in CORT-treated PC12 cells. (A) CSA was prepared at the indicated times after exposure to CORT, and cytoplasmic cytochrome $c$, cleaved ICAD, $\beta$-actin were detected by immunoblotting. (B) The cleaved ICAD data are presented as fold-changes compared to the $\beta$-actin in the control group. (C) Cytoplasmic cytochrome $c$ data are presented as foldchanges compared to the $\beta$-actin. (D) Caspase- 3 activity was detected using a commercial kit as described in Section 2. (E) Effect of CSA on the expression of Caspase-3 and cleaved Caspase-3 in PC12 cells. (F) The cleaved Caspase- 3 data are presented as percentage compared to the Caspase- 3 in each group. The data are presented as percentages relative to the control group. The data are presented as the means \pm the SDs $(n=3)$.

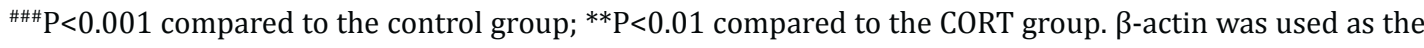
loading control in all experiments included in the vehicle, CORT and CSA treatments. CSA: cajaninstilbene acid, CORT: corticosterone, ICAD: Inhibitor of Caspase Activated Dnase.

results are consistent with the western blot assay, which showed that various concentrations of CSA significantly inhibited the expression of cleaved caspase-3 (Fig. 6E, 6F). These results indicate that CSA reduces mitochondrial apoptosis via the caspase-3 pathway by degrading ICAD, which inhibits the activation of caspase-activated deoxyribonuclease (CAD), resulting in DNA fragmentation.

\section{Discussion}

This study examined the neuroprotective effects of CSA on the cytotoxicity induced by CORT in PC12 cells, yielding novel findings regarding the pharmacological properties 
of CSA. CSA exerted neuroprotective effects partially through (1) the antagonism of $\left[\mathrm{Ca}^{2+}\right]_{i}$ overloading and (2) the inhibition of mitochondrial-dependent apoptosis in PC12 cells. Although the cellular and molecular mechanisms underlying the action of CSA have not been fully elucidated to date, our results suggest that several mechanisms, either working separately or together, may play roles in the neuroprotective effects of CSA.

The precise cellular mechanisms underlying corticosteroid-induced neuronal damage have not been fully described. Substantial evidence indicates that CORT is also involved the deregulation of $\mathrm{Ca}^{2+}$ homeostasis $[25,26]$. CORT-induced apoptosis in PC12 cells involves the production of reactive oxygen species (ROS) and the up-regulation of nerve growth factor (NGF) expression [27]. Recently, it has been reported that CORT induces apoptosis in cultured hippocampal neurons through the blockade of p38 MAPK activation and the induction of mitochondrial dysfunction, including increasing $\Delta \Psi \mathrm{m}$ and inhibiting caspase-3 activation [28]. Furthermore, CORT was shown to be involved in the fragmentation of DNA, the induction of $\mathrm{Bax} / \mathrm{Bcl}-2, \mathrm{Ca}^{2+}$ deregulation, the abnormal opening of mPTPs and the disruption of $\triangle \Psi \mathrm{m}$ in PC12 cells [29]. Here, we describe a protective effect by which naturally occurring CSA ameliorates CORT-induced neurotoxicity in PC12 cells.

It is widely accepted that neuronal degeneration after CORT administration is associated with the accumulation of $\mathrm{Ca}^{2+}$ in neurons. This increase in intracellular $\mathrm{Ca}^{2+}$ can induce mitochondrial dysfunction via the activation of mPTPs, which results in a cascade of reactions that lead to cell death [30-32]. Moreover, the observed $\Delta \Psi \mathrm{m}$ is thought to be mediated by the opening of mPTPs [31-33], and reductions in $\Delta \Psi \mathrm{m}$ that accompany early apoptosis have been reported under different conditions [31, 32, 34]. We found that intracellular $\mathrm{Ca}^{2+}$ concentrations were significantly higher in cells treated with CORT, which also caused pathological and abnormal opening of mPTPs and disruptions of $\triangle \Psi \mathrm{m}$ in PC12 cells (Figs. 4 and 5). These results are in agreement with previous findings that mostly focused on $\mathrm{Ca}^{2+}$ and mitochondrial function $[25,29,35,36]$. Perhaps the most significant finding in the present study was that both an increase in cytosolic $\mathrm{Ca}^{2+}$ concentration and disruption of mitochondrial function following exposure to CORT were blocked by subsequent CSA treatment, suggesting that CSA may exert a neuroprotective effect through the blockade of $\left[\mathrm{Ca}^{2+}\right]_{\mathrm{i}}$ overload and mitochondrial dysfunction (Fig. 7).

Increasing evidence suggests that CORT-induced apoptosis plays a key role in the induction of hippocampal neuronal damage in vivo and in vitro [37-39]. Permeability changes in mitochondria lead to the release of pro-apoptotic molecules, such as cytochrome c, from the mitochondria into the cytosol, which results in the induction of caspasedependent cytotoxicity and downstream apoptotic signalling [40, 41]. In the present study, using Hoechst 33342 staining, we observed morphological changes in PC12 cells following CORT treatment; these cells displayed apparent morphological features typical of apoptosis, including considerable cell loss, neurite injury and cell body shrinkage (Fig. 3A). Moreover, CORT administration led to an increase in cytoplasmic cytochrome c and an increase in caspase-3 activity, consistent with previous reports [42]. In the final phase of apoptosis, caspases induce DNA fragmentation via CAD activation $[43,44]$. In growing cells, CAD remains inactive and forms an inactive cytoplasmic heterodimer with ICAD [45]; however, during apoptosis, caspase- 3 cleaves ICAD and releases it from CAD. CAD then forms an active homodimeric endonuclease in the nucleus that causes DNA fragmentation [46]. Our data suggest that CSA inhibits the CORT-induced expression of cytoplasmic cytochrome c. In 


\section{Cellular Physiology and Biochemistry}

Cell Physiol Biochem 2014;34:1015-1026

\begin{tabular}{l|l}
\hline DOI: $10.1159 / 000366317$ & (C) 2014 S. Karger AG, Basel
\end{tabular}

www.karger.com/cpb

Jiang et al.: CSA Prevents Apoptosis by Inhibiting the Mitochondrial Apoptotic Pathway

addition, the CSA-induced decreases in ICAD and caspase- 3 activities are in agreement with the above notions. The present in vitro results demonstrated that the neuroprotective action of CSA against CORT can be at least partially attributed to a reduction in apoptosis, as CSA decreased CORT-induced caspase-3 activation (Fig. 6).

Previous studies have shown that CSA has stronger antioxidant properties than resveratrol [47], which can be attributed to its structural characteristics, such as the conjugation between rings A and B via a planar C2 unsaturated structure [48], the presence of a 5-hydroxyl group in the A ring [49] and methoxy groups at the 3-position [50]. As many studies have evaluated the relationship between antioxidants and the mitochondrial apoptosis pathway [51-53], we hypothesised that CSA-mediated neuroprotection may result from its strong antioxidant effects, which inhibit mitochondrial apoptosis. In summary, our data support a mechanism for the CSA-mediated suppression of CORT-induced apoptosis, which is illustrated in Fig. 7. The present study provides novel evidence showing that CSA protects PC12 cells in vitro, likely through both the antagonism of $\left[\mathrm{Ca}^{2+}\right]_{i}$ overload and the inhibition of cellular pathways in association with cytochrome c, caspase-3 and ICAD. Further studies may provide important evidence to support the notion that the inhibition of mitochondrial pathways directly contributes to the anti-apoptotic effects of CSA through the downstream apoptosis signalling cascade or as a result of reactions upstream of the apoptosis cascade.

This study indicates that CSA-mediated cytoprotection may be one of the mechanisms of its antidepressant-like effects. Based on clinical and animal observations as well as our results, further studies with CSA are warranted and may lead to the development of novel antidepressants.

\section{Acknowledgments}

This work was financially supported by National Science and Technology major projects (2012ZX09301002-001 and 2011ZX09307-002-01) and the International Science and Technology Cooperation of China (1108 and 2011DFA32730).

\section{References}

1 Gao M, Zhou H, Li X: Curcumin protects pc12 cells from corticosterone-induced cytotoxicity: possible involvement of the erk1/2 pathway. Basic Clin Pharmacol Toxicol 2009;104:236-240.

2 Zhu MY, Wang WP, Bissette G: Neuroprotective effects of agmatine against cell damage caused by glucocorticoids in cultured rat hippocampal neurons. Neuroscience 2006;141:2019-2027.

-3 Murray F, Smith DW, Hutson PH: Chronic low dose corticosterone exposure decreased hippocampal cell proliferation, volume and induced anxiety and depression like behaviours in mice. Eur J Pharmacol 2008;583:115-127.

4 Lee Y, Gustafsson ASB: Role of apoptosis in cardiovascular disease. Apoptosis 2009;14:536-548.

-5 Chen H, Pandey GN, Dwivedi Y: Hippocampal cell proliferation regulation by repeated stress and antidepressants. Neuroreport 2006;17:863-867.

-6 Grover JK, Yadav S, Vats V: Medicinal plants of india with anti-diabetic potential. J Ethnopharmacol 2002;81:81-100.

7 Tang Y, Wang B, Zhou XJ: Effect of external application of herbal cajani preparation on the fibronection content during healing process of open wound. J Guangzhou Univ Tradit Chin Med 1999;16:302-304.

8 Zhang D, Zhang S, Zu Y, Fu Y, Kong Y, Gao Y, Zhao J: Negative pressure cavitation extraction and antioxidant activity of genistein and genistin from the roots of pigeon pea [cajanus cajan (l.) Millsp.]. Sep Purif Technol 2010;74:261-270.

-9 Duker-Eshun G, Jaroszewski JW, Asomaning WA, Oppong-Boachie F, Brogger CS: Antiplasmodial constituents of cajanus cajan. Phytother Res 2004;18:128-130. 


\section{Cellular Physiology and Biochemistry}

Cell Physiol Biochem 2014;34:1015-1026

\begin{tabular}{l|l}
\hline DOI: $10.1159 / 000366317$ & (C) 2014 S. Karger AG, Basel
\end{tabular}

www.karger.com/cpb

Jiang et al.: CSA Prevents Apoptosis by Inhibiting the Mitochondrial Apoptotic Pathway

10 Kong Y, Fu YJ, Zu YG, Chang FR, Chen YH, Liu XL, Stelten J, Schiebel HM: Cajanuslactone, a new coumarin with anti-bacterial activity from pigeon pea [cajanus cajan (l.) Millsp.] Leaves. Food Chem 2010;121:11501155.

11 Khadem S, Marles RJ: Monocyclic phenolic acids; Hydroxy- and polyhydroxybenzoic acids: occurrence and recent bioactivity studies. Molecules 2010;15:7985-8005.

12 Zheng YY, Yang J, Chen DH, Sun L: [effects of the stilbene extracts from cajanus cajan l. On ovariectomyinduced bone loss in rats]. Yao Xue Xue Bao 2007;42:562-565.

13 Ruan CJ, Si JY, Zhang L, Chen DH, Du GH, Su L: Protective effect of stilbenes containing extract-fraction from cajanus cajan l. On abeta (25-35)-induced cognitive deficits in mice. Neurosci Lett 2009;467:159-163.

14 Zhu W, Ma S, Qu R, Kang D: Antidepressant-like effect of saponins extracted from chaihu-jia-longgu-mulitang and its possible mechanism. Life Sci 2006;79:749-756.

15 Li YF, Liu YQ, Yang M, Wang HL, Huang WC, Zhao YM, Luo ZP: The cytoprotective effect of inulintype hexasaccharide extracted from morinda officinalis on pc12 cells against the lesion induced by corticosterone. Life Sci 2004;75:1531-1538.

16 Li YF, Gong ZH, Yang M, Zhao YM, Luo ZP: Inhibition of the oligosaccharides extracted from morinda officinalis, a chinese traditional herbal medicine, on the corticosterone induced apoptosis in pc12 cells. Life Sci 2003;72:933-942.

17 Evanson NK, Tasker JG, Hill MN, Hillard CJ, Herman JP: Fast feedback inhibition of the hpa axis by glucocorticoids is mediated by endocannabinoid signaling. Endocrinology 2010;151:4811-4819.

18 Czeh B, Lucassen PJ: What causes the hippocampal volume decrease in depression? Are neurogenesis, glial changes and apoptosis implicated? Eur Arch Psychiatry Clin Neurosci 2007;257:250-260.

19 Swaab DF, Bao AM, Lucassen PJ: The stress system in the human brain in depression and neurodegeneration. Ageing Res Rev 2005;4:141-194.

20 Strohle A, Holsboer F: Stress responsive neurohormones in depression and anxiety. Pharmacopsychiatry 2003;36:S207-S214.

21 Jiang BP, Liu YM, Li ZY, Song B: Protective effect of alcohol extract of cajanus cajan on corticosteroneinduced lesion in cultured pc12 cells. Nat Prod Res Dev 2012;24:1270-1273, 1291.

22 Wieckowski MR, Giorgi C, Lebiedzinska M, Duszynski J, Pinton P: Isolation of mitochondria-associated membranes and mitochondria from animal tissues and cells. Nat Protoc 2009;4:1582-1590.

23 Bradford MM: A rapid and sensitive method for the quantitation of microgram quantities of protein utilizing the principle of protein-dye binding. Anal Biochem 1976;72:248-254.

24 Ryter SW, Kim HP, Hoetzel A, Park JW, Nakahira K, Wang X, Choi AM: Mechanisms of cell death in oxidative stress. Antioxid Redox Signal 2007;9:49-89.

25 Zhu MY, Wang WP, Bissette G: Neuroprotective effects of agmatine against cell damage caused by glucocorticoids in cultured rat hippocampal neurons. Neuroscience 2006;141:2019-2027.

26 Zeng J, Li M, Xiao Z, Chen Y, Chang Q Tian H, Jin H, Liu X: Rapid elevation of calcium concentration in cultured dorsal spinal cord astrocytes by corticosterone. Neurochem Res 2013;38:382-388.

27 Mao QQ Zhong XM, Qiu FM, Li ZY, Huang Z: Protective effects of paeoniflorin against corticosteroneinduced neurotoxicity in pc12 cells. Phytother Res 2012;26:969-973.

28 Liu B, Zhang H, Xu C, Yang G, Tao J, Huang J, Wu J, Duan X, Cao Y, Dong J: Neuroprotective effects of icariin on corticosterone-induced apoptosis in primary cultured rat hippocampal neurons. Brain Res 2011;1375:5967.

29 Li ZY, Guo Z, Liu YM, Liu XM, Chang Q Liao YH, Pan RL: Neuroprotective effects of total saikosaponins of bupleurum yinchowense on corticosterone-induced apoptosis in pc12 cells. J Ethnopharmacol 2013;148:794-803.

-30 Liang L, Luo M, Fu Y, Zu Y, Wang W, Gu C, Zhao C, Li C, Efferth T: Cajaninstilbene acid (csa) exerts cytoprotective effects against oxidative stress through the nrf2-dependent antioxidant pathway. Toxicol Lett 2013;219:254-261.

-31 Zhang DM, Li Y, Cheang WS, Lau CW, Lin SM, Zhang QL, Yao N, Wang Y, Wu X, Huang Y, Ye WC: Cajaninstilbene acid relaxes rat renal arteries: roles of $\mathrm{Ca}^{2+}$ antagonism and protein kinase c-dependent mechanism. PLoS One 2012;7:e47030.

-32 Gunter TE, Gunter KK, Sheu S, Gavin CE: Mitochondrial calcium transport: physiological and pathological relevance. Am J Physiol-Cell Ph 1994;267:C313-C339. 


\section{Cellular Physiology and Biochemistry}

Cell Physiol Biochem 2014;34:1015-1026

\begin{tabular}{l|l}
\hline DOI: $10.1159 / 000366317$ & (c) 2014 S. Karger AG, Basel
\end{tabular}

Jiang et al.: CSA Prevents Apoptosis by Inhibiting the Mitochondrial Apoptotic Pathway

$>33$

$>34$

35 Zamzami N, Susin SA, Marchetti P, Hirsch T, Gomez-Monterrey I, Castedo M, Kroemer G: Mitochondrial control of nuclear apoptosis. J Exp Med 1996;183:1533-1544.

-36 Kroemer G, Zamzami N, Susin SA: Mitochondrial control of apoptosis. Immunol Today 1997;18:44-51.

-37 Zhu ZH, Yang R, Fu X, Wang YQ, Wu GC: Astrocyte-conditioned medium protecting hippocampal neurons in primary cultures against corticosterone-induced damages via pi3-k/akt signal pathway. Brain Res 2006;1114:1-10.

-38 Crochemore C, Lu J, Wu Y, Liposits Z, Sousa N, Holsboer F, Almeida OF: Direct targeting of hippocampal neurons for apoptosis by glucocorticoids is reversible by mineralocorticoid receptor activation. Mol Psychiatry 2005;10:790-798.

-39 Reagan LP, McEwen BS: Controversies surrounding glucocorticoid-mediated cell death in the hippocampus. J Chem Neuroanat 1997;13:149-167.

40 Kluck RM, Bossy-Wetzel E, Green DR, Newmeyer DD: The release of cytochrome c from mitochondria: a primary site for bcl-2 regulation of apoptosis. Science 1997;275:1132-1136.

-41 Kluck RM, Martin SJ, Hoffman BM, Zhou JS, Green DR, Newmeyer DD: Cytochrome c activation of cpp32like proteolysis plays a critical role in a xenopus cell-free apoptosis system. EMBO J1997;16:4639-4649.

-42 Pal S, Ahir M, Sil PC: Doxorubicin-induced neurotoxicity is attenuated by a 43-kd protein from the leaves of cajanus indicus l. Via nf-kappab and mitochondria dependent pathways. Free Radic Res 2012;46:785-798.

43 Enari M, Sakahira H, Yokoyama H, Okawa K, Iwamatsu A, Nagata S: A caspase-activated dnase that degrades dna during apoptosis, and its inhibitor icad. Nature 1998;391:43-50.

44 Sakahira H, Enari M, Nagata S: Cleavage of cad inhibitor in cad activation and dna degradation during apoptosis. Nature 1998;391:96-99.

45 Liu X, Zou H, Slaughter C, Wang X: Dff, a heterodimeric protein that functions downstream of caspase-3 to trigger dna fragmentation during apoptosis. Cell 1997;89:175-184.

-46 Lechardeur D, Drzymala L, Sharma M, Zylka D, Kinach R, Pacia J, Hicks C, Usmani N, Rommens JM, Lukacs GL: Determinants of the nuclear localization of the heterodimeric dna fragmentation factor (icad/cad). J Cell Biol 2000;150:321-334.

47 Wu N, Kong Y, Fu Y, Zu Y, Yang Z, Yang M, Peng X, Efferth T: In vitro antioxidant properties, dna damage protective activity, and xanthine oxidase inhibitory effect of cajaninstilbene acid, a stilbene compound derived from pigeon pea [cajanus cajan (1.) Millsp.] Leaves. J Agric Food Chem 2011;59:437-443.

-48 Waffo TP, Fauconneau B, Deffieux G, Huguet F, Vercauteren J, Merillon JM: Isolation, identification, and antioxidant activity of three stilbene glucosides newly extracted from vitis vinifera cell cultures. J Nat Prod 1998;61:655-657.

-49 Queiroz AN, Gomes BA, Moraes WJ, Borges RS: A theoretical antioxidant pharmacophore for resveratrol. Eur J Med Chem 2009;44:1644-1649.

50 Hasiah AH, Ghazali AR, Weber JF, Velu S, Thomas NF, Inayat HS: Cytotoxic and antioxidant effects of methoxylated stilbene analogues on hepg2 hepatoma and chang liver cells: implications for structure activity relationship. Hum Exp Toxicol 2011;30:138-144.

51 Tucci P, Cione E, Perri M, Genchi G: All-trans-retinoic acid induces apoptosis in leydig cells via activation of the mitochondrial death pathway and antioxidant enzyme regulation. J Bioenerg Biomembr 2008;40:315323.

-52 Kadara H, Lacroix L, Lotan D, Lotan R: Induction of endoplasmic reticulum stress by the pro-apoptotic retinoid n-(4-hydroxyphenyl)retinamide via a reactive oxygen species-dependent mechanism in human head and neck cancer cells. Cancer Biol Ther 2007;6:705-711.

53 Wang YG, Li Y, Wang CY, Ai JW, Dong XY, Huang HY, Feng ZY, Pan YM, Lin Y, Wang BX, Yao LL: L-3-nbutylphthalide protects rats' cardiomyocytes from ischaemia/reperfusion-induced apoptosis by affecting the mitochondrial apoptosis pathway. Acta Physiol (Oxf) 2014;210:524-533. 